\title{
Cyclohexane as an Alternative Vapor of Carbon Tetrachloride for the Assessment of Gas Removing Capacities of Gas Masks
}

\author{
Mitsuya FURUSE ${ }^{1 *}$, Seiichiro KANNO ${ }^{1}$, Tsuguo TAKANO$^{1}$ and Yoshimi MATSUMURA ${ }^{2}$ \\ ${ }^{1}$ National Institute of Industrial Health, 21-1, Nagao 6-chome, Tama-ku, Kawasaki 214-8585, Japan \\ ${ }^{2}$ Kawasaki Respirator Test Laboratory, The Technology Institution of Industrial Safety, KSP 1011A, 3-2-1, Sakato, \\ Takatsu-ku, Kawasaki 213-0012, Japan
}

Received August 31, 2000 and accepted December 12, 2000

\begin{abstract}
An alternative vapor was explored to replace carbon tetrachloride $\left(\mathrm{CCl}_{4}\right)$ for testing breakthrough times of cartridges and canisters of gas masks in the National Approval Test of Respirators. Cyclohexane was single out as a candidate for the alternative vapor out of six vapors: trichloroethylene, n-pentane, $n$-hexane, $n$-heptane, toluene and cyclohexane from the viewpoints of similarity of vapor pressure and water-solubility to $\mathrm{CCl}_{4}$, lower toxicity than $\mathrm{CCl}_{4}$, and technical feasibility in generating an airflow of $30 \mathrm{~L} / \mathrm{min}$ containing the vapor ranging from 300 to $5000 \mathrm{ppm}$. Breakthrough times of cartridges and canisters were examined by generating cyclohexane vapor in a test airflow of $30 \mathrm{~L} / \mathrm{min}$ in comparison with $\mathrm{CCl}_{4}$ vapor under various test conditions with different vapor concentrations and relative humidities $(\mathrm{RH})$. As the results, the breakthrough times of the cartridges and canisters for cyclohexane were found to almost coincide with those for $\mathrm{CCl}_{4}$ under all examined range of concentrations and RH. By an increase of humidity from $50 \% \mathrm{RH}$ to $80 \% \mathrm{RH}$, the cartridges showed significant shortening of breakthrough times for both of $\mathrm{CCl}_{4}$ and cyclohexane, but the susceptibility of the breakthrough time of cyclohexane to humidity was also similar to that of $\mathrm{CCl}_{4}$. It was, therefore, concluded that cyclohexane can be recommended as the alternative vapor of $\mathbf{C C l}_{4}$ for testing the breakthrough times of gas mask cartridges and canisters in the National Approval Test.
\end{abstract}

Key words: Gas mask, Cartridge, Canister, Carbon tetrachloride, Cyclohexane, Breakthrough time, Respirator

\section{Introduction}

Carbon tetrachloride $\left(\mathrm{CCl}_{4}\right)$ vapor has long been used as a representative organic vapor for testing breakthrough times of gas mask cartridges and canisters in the National Approval Test of Respirators as well as in respirator tests in manufactures. However, the production and use of $\mathrm{CCl}_{4}$ in industries are now phased out, because of its potentially significant depleting effect on stratospheric ozone ${ }^{1,2)}$, and because of its suspected human carcinogenicity ${ }^{3)}$. This study was funded by the Ministry of Labour to establish a new

*To whom correspondence should be addressed. test method of gas masks without the use of $\mathrm{CCl}_{4}$. To keep the continuity of the quality criteria of gas masks through the change of the test method was the requirement of the National Approval Test System. Besides, the deterioration of the gas removing capacities of cartridges and canisters by the airborne moisture should be detected similarly by the new method as by the $\mathrm{CCl}_{4}$ method. Similarity of vapor pressure and water-insolubility to $\mathrm{CCl}_{4}$, technical feasibility in generating a test airflow containing the vapor ranging from 300 to $5000 \mathrm{ppm}(\mathrm{v} / \mathrm{v})$, and the lower risk in toxicity, carcinogenicity and flammability are the primary requirement to single out a $\mathrm{CCl}_{4}$ replacement vapor. At first, the six candidates of alternatives were chosen within these scopes. 
They were trichloroethylene, n-pentane, n-hexane, cyclohexane, $\mathrm{n}$-heptane and toluene. Among the candidates, n-pentane has very low boiling point of $36.06^{\circ} \mathrm{C}$ which is close to the climatic temperature in the summer in Japan and its handling in laboratory is difficult. To obtain 5000 ppm vapor concentration of toluene in the test airflow of $30 \mathrm{~L} /$ min needs the higher evaporation temperature than the laboratory ambient temperature and consequently, the vapor tends to condense in the downstream pipes kept at $20^{\circ} \mathrm{C}$. By these reasons relating their volatility, $\mathrm{n}$-pentane and toluene were excluded from the candidates. Trichloroethylene and $\mathrm{n}$-hexane were taken as the second candidates due to their higher toxicity. Cyclohexane and n-heptane were experimentally examined for the test of breakthrough times of gas masks in comparison with $\mathrm{CCl}_{4}$. The Notification of The Ministry of Labour on Standards of Gas Masks for the National Approval Test stipulated in $1990^{4)}$ requires that the breakthrough time of $\mathrm{CCl}_{4}$ be longer than 50 minutes for cartridges with the $\mathrm{CCl}_{4}$ concentration of $300 \mathrm{ppm}$ in a test airflow, longer than $30 \mathrm{~min}$ for chin-style canisters with 3000 $\mathrm{ppm} \mathrm{CCl}_{4}$, and longer than 100 min for front-mounted or backmounted (FM/BM) canisters with $5000 \mathrm{ppm} \mathrm{CCl}_{4}$, at the airflow of $30 \mathrm{~L} / \mathrm{min}$. In the present experiment, cyclohexane was examined for breakthrough times of commercially available gas mask cartridges and canisters in comparison to $\mathrm{CCl}_{4}$ at certain concentration ranges of vapors and coexistent moisture. n-Heptane was also applied for the test, but finally it was excluded from the candidate due to the technical difficulty in generating vapor at high concentration.

\section{Materials and Methods}

\section{Apparatus for measuring breakthrough times of respirator cartridges and canisters}

Figure 1 illustrates a schematic diagram of a testing apparatus for measuring breakthrough times of respirator cartridges and canisters. The apparatus is consisted of two parts; one for generating an airflow containing an organic vapor at a constant concentration with constant $\mathrm{RH}$, and the other for testing breakthrough time of a cartridge or canister by passing the organic vapor-containing airflow through a test piece mounted in a thermostatic air box and by monitoring the exit vapor concentration by a gas chromatograph (GC) (Type 5890 Series II, Hewlett-Packard, USA). A test airflow with a certain vapor concentration and a constant RH was obtained by the former part of the apparatus by mixing two controlled airflows; one airflow was saturated with water vapor at $20^{\circ} \mathrm{C}$ and at a certain pressure up to $338 \mathrm{kPa}$ and then reduced to the atmospheric

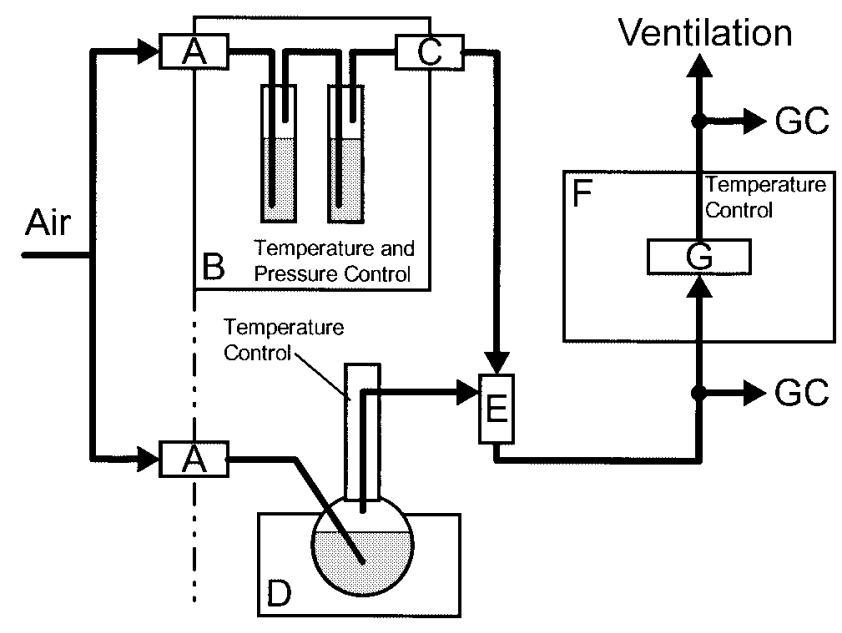

Fig. 1. A schematic diagram of the apparatus for generating test airflow.

A: Airflow controllers, B: Two pressurized humidifier in series containing distilled water $\left(20^{\circ} \mathrm{C}, 127 \sim 337 \mathrm{kPa}\right), \mathrm{C}$ : Back pressure regulator, D: Reflux condenser, E: Gas mixing tube, F: Thermostatic air box $\left(20^{\circ} \mathrm{C}\right)$, G: Test piece of gas mask cartridge or canister.

pressure, and the other airflow was saturated with the test vapor at a certain temperature below the ambient temperature. These two flows were mixed in a gas mixing tube to get a test airflow. The concentration of an organic vapor in the test airflow was measured every 3 minutes at the downstream of the mixing tube with a GC equipped with an automatic gas sampling device and a hydrogen flame ionization detector (FID). Then, the test airflow was introduced into the latter part of the apparatus for testing breakthrough times of cartridges and canisters. In this study, the test airflow entering the thermostatic air box was regulated at a temperature of $20^{\circ} \mathrm{C}$ and a flow rate of $30 \mathrm{~L} / \mathrm{min}$ with constant RH of 30 , 50,70 or $80 \% . \mathrm{CCl}_{4}$ and cyclohexane vapors in the airflow were regulated precisely at the suitable concentrations required for the classes of cartridges and canisters, i.e., cartridges were tested in the concentration range from 100 to $600 \mathrm{ppm}$, chin-style canisters in the range from 1000 to $5000 \mathrm{ppm}$ and $\mathrm{FM} / \mathrm{BM}$ canisters in the range from 3000 to $8000 \mathrm{ppm}$. $\mathrm{CCl}_{4}$, cyclohexane and n-heptane used in the present study were of reagent grade (Wako Pure Chemical, Japan). However, $n$-heptane vapor could not be generated enough to prepare $5000 \mathrm{ppm}$ test airflow due to its lower volatility, though it could be generated within the concentration range from 150 to $620 \mathrm{ppm}$ in the test airflow. By this reason, we did not examine n-heptane further.

\section{Measurement of breakthrough time}

After a test piece of cartridge or canister was mounted to 
Table 1. Classes and sizes of respirator cartridges and canisters tested in the present study

\begin{tabular}{|c|c|c|c|c|}
\hline $\begin{array}{c}\text { Classes of cartridge } \\
\text { or canister }\end{array}$ & Manufacturer & $\begin{array}{c}\text { Number of cartridges } \\
\text { or canisters used }\end{array}$ & $\begin{array}{l}\text { Size of activated } \\
\text { carbon container }\end{array}$ & $\begin{array}{c}\text { Content of } \\
\text { activated carbon }\end{array}$ \\
\hline Cartridge & A & 28 & $\begin{array}{l}75.2 \mathrm{~mm}(\phi) \\
15 \mathrm{~mm} \text { (Thickness) }\end{array}$ & $23 \mathrm{~g}$ \\
\hline Cartridge & B & 42 & $\begin{array}{l}77 \mathrm{~mm}(\phi) \\
20 \mathrm{~mm} \text { (Thickness) }\end{array}$ & $41 \mathrm{~g}$ \\
\hline Chin-style canister & $\mathrm{C}$ & 16 & $\begin{array}{l}85 \mathrm{~mm}(\phi) \\
35 \mathrm{~mm} \text { (Thickness) }\end{array}$ & $80 \mathrm{~g}$ \\
\hline FM/BM canister & B & 12 & $\begin{array}{l}135 \mathrm{~mm} \text { (Length) } \\
75 \mathrm{~mm} \text { (Width) } \\
114 \mathrm{~mm} \text { (Thickness) }\end{array}$ & $312 \mathrm{~g}$ \\
\hline FM/BM canister & $\mathrm{C}$ & 16 & $\begin{array}{l}145 \mathrm{~mm} \text { (Length) } \\
76 \mathrm{~mm} \text { (Width) } \\
68 \mathrm{~mm} \text { (Thickness) }\end{array}$ & $270 \mathrm{~g}$ \\
\hline
\end{tabular}

FM/BM canister: front-mounted or back-mounted canister.

the test line in the thermostatic air box, the airflow containing an organic vapor of a constant concentration with constant RH was introduced through it. The concentration of the organic vapor was measured every 3 minutes at a sampling port located at the exit of the test piece with the same GC used for the test airflow monitoring. The breakthrough limit concentration at the exit of the cartridge and canister to determine the breakthrough times for both of $\mathrm{CCl}_{4}$ and cyclohexane were set at $10 \mathrm{ppm}$ in this study. The breakthrough times were measured in relation to the concentration of the vapor and humidity in the test airflow.

\section{Respirator cartridges and canisters tested}

Table 1 shows classes, sizes, activated carbon contents and number of respirator cartridges and canisters tested in the present study, which were commercially purchased in the market. We used three classes of cartridges and canisters manufactured by Japanese companies A, B and C, i.e., two kinds of cartridges, a kind of chin-style canister and two kinds of FM/BM canisters. The cartridges and canisters were submitted to the test "as purchased".

\section{Results}

Stability and reproducibility of concentrations of organic vapors in the test airflow

Stability of the vapor concentration in the test airflow was monitored as the variation coefficient (CV). Taking the air sample every 3 minutes during 2 or 3 hours of constant running of the test airflow generating apparatus, the $\mathrm{CV}$ of the vapor concentration was found to be $1.22 \%$ for timeaveraged concentration of $285 \mathrm{ppm}$ for intended concentration of $300 \mathrm{ppm}$ cyclohexane vapor in the test airflow. The CVs of cyclohexane vapor at different concentrations as well as those of $\mathrm{CCl}_{4}$ and n-heptane were also found to be within the same range from 1 to $3 \%$. As to reproducibility in generating the test airflow, day-to-day variations of $\mathrm{CCl}_{4}$ and cyclohexane concentrations in the airflow were found to be within the range from 1 to $4 \%$. High reproducibility of the vapor concentration in the test airflow was also indicated by the breakthrough curves obtained by duplicated measurements in Fig. 2 which agreed well with each other. This means that the apparatus generated a stable and reproducible test airflow containing an organic vapor at a satisfactorily constant concentration.

\section{Breakthrough curves}

Figure 2 shows breakthrough curves of $\mathrm{CCl}_{4}$ and cyclohexane as a function of time elapsed from the start of passing the test airflow through the cartridge manufactured by A. All the four breakthrough concentration-time relationships were found to follow sigmoidal curves, indicating three distinct stages in the breakthrough concentrations: The first stage is characterized by the beginning of the test vapor leakage into the exit airflow whose concentration increases slowly. In the practical uses of gas masks, cartridges or canisters should be replaced with a new one at this stage before the exit vapor concentration reaches to the noxious level to the users. After this first stage, the exit vapor concentration rapidly rises and then reached to a plateau level approximated to the inlet concentration. The breakthrough times of the cartridges or canisters are defined as those when the vapor begins to leak from the test piece at the maximum permissible concentrations for the wearers 


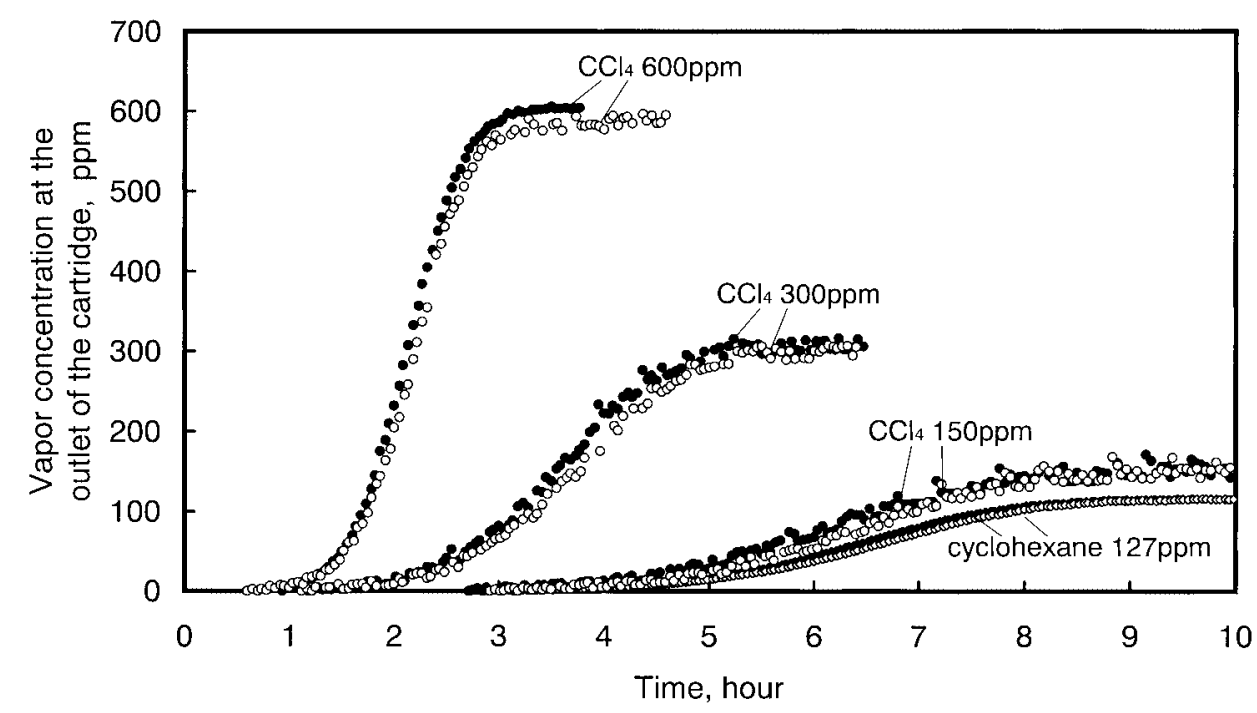

Fig. 2. Vapor concentrations of carbon tetrachloride and cyclohexane at the outlet of the cartridge A. Temperature, relative humidity and the airflow rate: $20^{\circ} \mathrm{C}, 50 \%$ and $30 \mathrm{~L} / \mathrm{min}$, respectively. : the first measurement, $\bigcirc$ : the second measurement.

on principle, but conventionally at $10 \mathrm{ppm}$ in this study.

\section{Breakthrough times for $\mathrm{CCl}_{4}$ and cyclohexane}

Figure 3 shows relationships between the breakthrough times of cartridge $\mathrm{A}$ and the vapor concentrations of $\mathrm{CCl}_{4}$ and cyclohexane in the test airflow. The breakthrough times of cartridge $\mathrm{A}$ for cyclohexane under two different $\mathrm{RH}$ conditions were found to agree well with those for $\mathrm{CCl}_{4}$. As shown in Fig. 4, it was also found with the cartridge manufactured by $\mathrm{B}$ that the breakthrough times for cyclohexane also agreed well with those for $\mathrm{CCl}_{4}$ under two different RH conditions. The comparison of Figs. 3 and 4 reveals that the breakthrough times of cartridge $B$ were longer than those of cartridge A. This difference can be attributed mainly to larger contents of activated carbon in the cartridge $\mathrm{B}$, as indicated in Table 1. Figure 5 shows relationship between the breakthrough times of chin-style canister $\mathrm{C}$ and the vapor concentrations of $\mathrm{CCl}_{4}$ and cyclohexane in the test airflow under two different RH conditions. The breakthrough times of the chin-style canister for these two vapors were found to agree well with each other. Figure 6 shows the breakthrough times of FM/BM canisters B and C as a function of vapor concentrations of $\mathrm{CCl}_{4}$ and cyclohexane under two different $\mathrm{RH}$ conditions. It was also confirmed that the breakthrough times of FM/BM canisters for cyclohexane were almost identical to those for $\mathrm{CCl}_{4}$.

\section{Effect of humidity}

Figures 3 and 4 show that the breakthrough times of cartridge A and cartridge B obtained by cyclohexane and $\mathrm{CCl}_{4}$ were shortened by an increase of $\mathrm{RH}$ from $50 \%$ to $80 \%$ in the airflow. These two figures reveal that the breakthrough times of cartridges and canisters for the test vapor in the lower concentration range are shortened significantly by the high humidity to the similar extents. Figures 5 and 6 indicate no apparent difference in the breakthrough times of chin-style and FM/BM canisters at $50 \%$ and $80 \% \mathrm{RH}$, in which the breakthrough times were observed at the higher vapor concentration ranges, and not susceptible to the effect of coexisting moisture. However, in Fig. 5, the breakthrough times for cyclohexane of 1000 ppm was slightly reduced at $80 \%$ RH for chin-style canister C. RH effect was further examined with cartridge B passing through the airflow containing cyclohexane with different RH ranging from 30 to $80 \%$. The result is shown in Fig. 7 . The significantly shortened breakthrough times were found only at a relative humidity higher than $50 \% \mathrm{RH}$ of the test airflow containing cyclohexane vapor lower than $400 \mathrm{ppm}$. In this result again, the effect of humidity at $70 \%$ and $80 \% \mathrm{RH}$ to shorten the breakthrough time was diminished according to the cyclohexane vapor concentration increase in the test airflow, and almost negligible at around $1000 \mathrm{ppm}$.

\section{Amounts of vapor adsorbed}

Figure 8 shows the amounts of $\mathrm{CCl}_{4}$ and cyclohexane adsorbed by cartridges, chin-style and FM/BM canisters. The amounts of vapors adsorbed by the activated carbon were calculated by the following equation: 


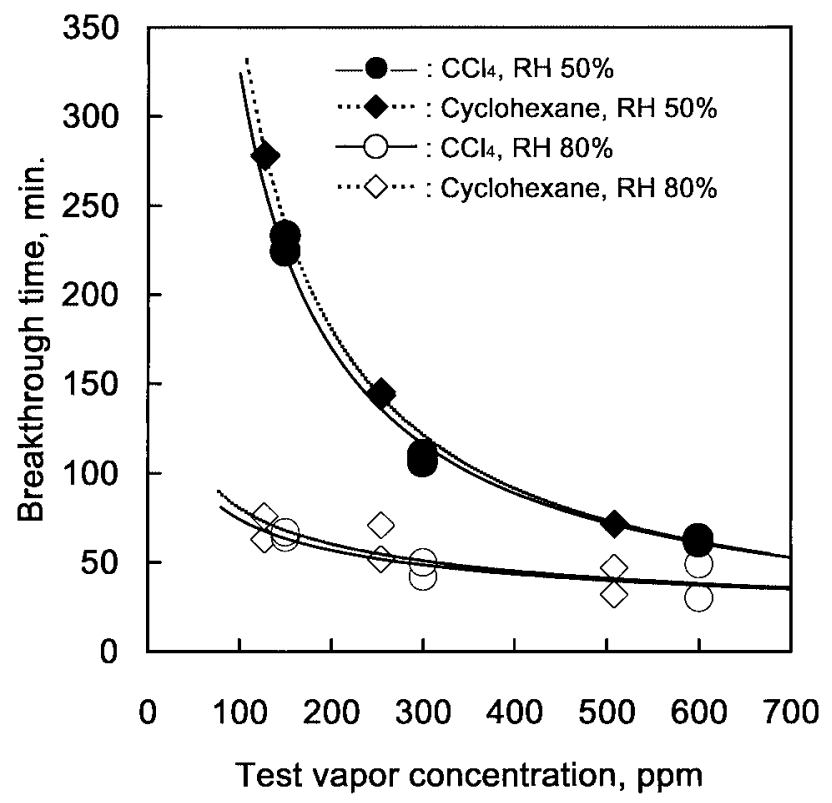

Fig. 3. Relationship between breakthrough times of cartridge $A$ and concentrations of carbon tetrachloride and cyclohexane in the airflow.

Temperature and the airflow rate: $20^{\circ} \mathrm{C}$ and $30 \mathrm{~L} / \mathrm{min}$, respectively.

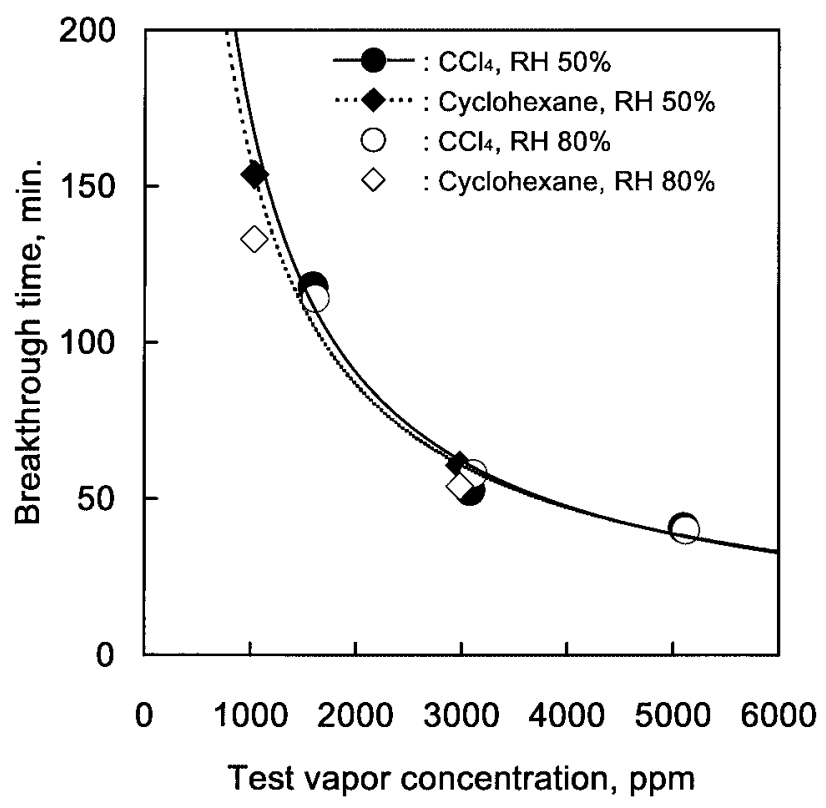

Fig. 5. Relationship between breakthrough times of chin-style canister $\mathbf{C}$ and concentrations of carbon tetrachloride and cyclohexane in the airflow.

Temperature and the airflow rate: the same as Fig. 3.

$$
\begin{aligned}
\text { [adsorbed amount }(\mathrm{L})] & =[\text { breakthrough time }(\min )] \\
& \times[\operatorname{airflow} \text { rate }(\mathrm{L} / \mathrm{min})] \\
& \times[\text { vapor concentration }(\mathrm{ppm})],
\end{aligned}
$$

then expressed as adsorbed capacity in mol. The adsorbed

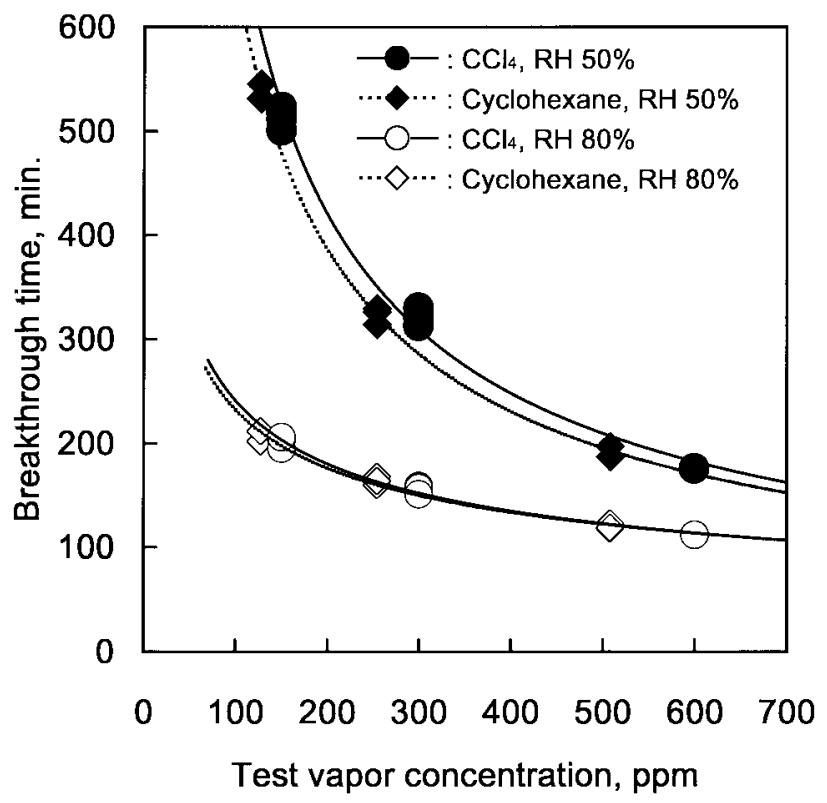

Fig. 4. Relationship between breakthrough times of cartridge $B$ and concentrations of carbon tetrachloride and cyclohexane in the airflow.

Temperature and the airflow rate: the same as Fig. 3.

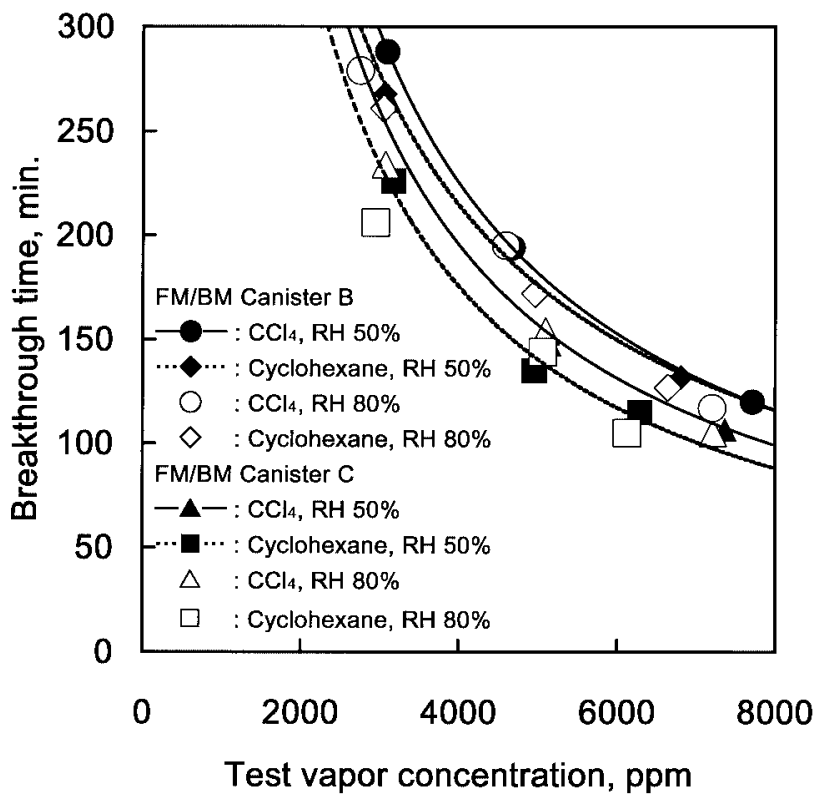

Fig. 6. Relationship between breakthrough times of front- or backmounted (FM/BM) canisters $B$ and $C$ and concentrations of carbon tetrachloride and cyclohexane in the airflow.

Temperature and the airflow rate: the same as Fig. 3.

amounts were found to vary, depending upon the amounts of activated carbon packed in the containers and the vapor concentration in the test airflow. The results indicate that the amount of $\mathrm{CCl}_{4}$ vapor adsorbed on each of the cartridges 


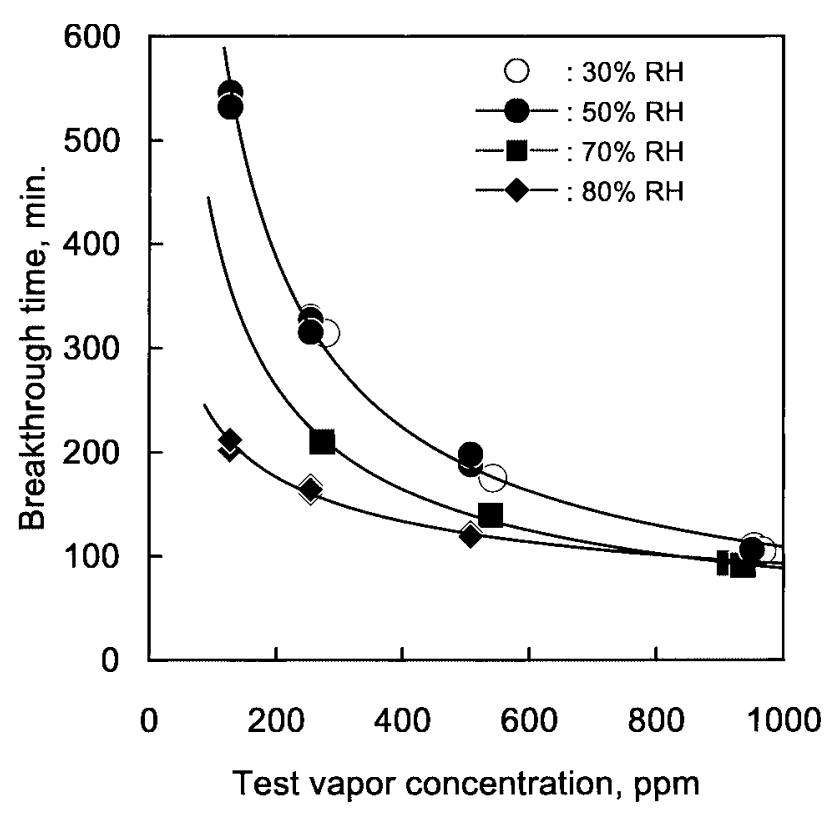

Fig. 7. Effect of relative humidity on breakthrough times of cartridge $B$ for cyclohexane vapor.

and canisters until the breakthrough time was in essential agreement with that of cyclohexane vapor adsorbed, with only a small difference between the two.

\section{Discussion}

In the present study, two steps of approaches were employed to single out a suitable $\mathrm{CCl}_{4}$ replacement vapor out of six candidate vapors: trichloroethylene, $n$-pentane, n-hexane, cyclohexane, n-heptane and toluene. The first step was based on reference to health and safety data of candidate vapors, similarity of physico-chemical properties of the candidate vapors to $\mathrm{CCl}_{4}$ which are related to the technical difficulty in generating an airflow containing an organic vapor by evaporation and refluxing method. Trichloroethylene and $n$-hexane were excluded due to their low exposure limit concentrations which were in the order of several tens ppm, lower than those of n-pentane, cyclohexane and $n$-heptane ${ }^{3,6)}$ by an order. Among cyclohexane, $n$-heptane and n-pentane which are flammable, $\mathrm{n}$-pentane is the most difficult material among them to handle with due to the high volatility at room temperature. Physicochemical properties such as water solubility and vapor pressure of cyclohexane are closer to those of $\mathrm{CCl}_{4}$ in comparison to those of n-pentane and n-heptane. Watersolubilities of cyclohexane, $\mathrm{n}$-heptane and n-pentane at $25^{\circ} \mathrm{C}$ are $0.010 \%, 0.00036 \%, 0.0038 \%(\mathrm{w} / \mathrm{w})$, respectively, in comparison to $0.077 \%$ of $\mathrm{CCl}_{4}{ }^{8}$; and the vapor pressures of

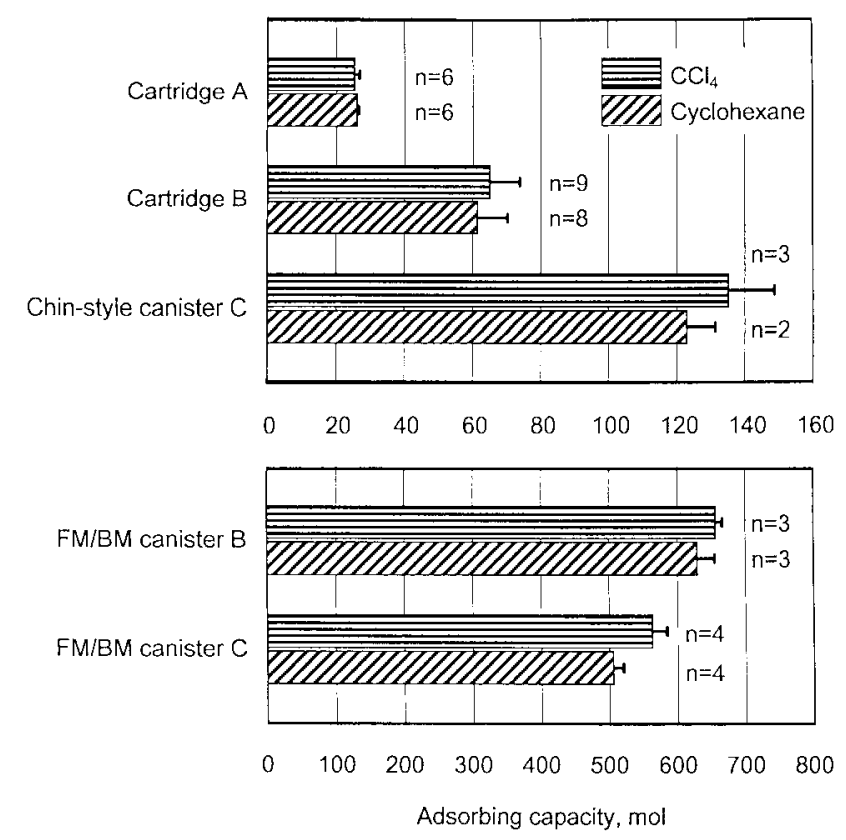

Fig. 8. Comparison of adsorbing capacities of $\mathrm{CCl}_{4}$ and cyclohexane vapor by cartridges, chin-style canisters and front-mounted or back-mounted (FM/BM) canisters.

The values are the mean \pm SD.

cyclohexane, $n$-heptane and n-pentane at $25^{\circ} \mathrm{C}$ are $13.0 \mathrm{kPa}$ $6.1 \mathrm{kPa}$ and $68.3 \mathrm{kPa}^{9}$ ), respectively, in comparison to 15.2 $\mathrm{kPa}$ of $\mathrm{CCl}_{4}$. The technical feasibility of generating an airflow of $30 \mathrm{~L} / \mathrm{min}$ containing the test vapor in a wide range of concentration in use of evaporation and refluxing method is a basic requirement for the $\mathrm{CCl}_{4}$ replacement vapor with minimal changes in any other procedures and conditions for National Approval Test which should evaluate the same critical levels of the gas removing capacities of cartridges and canisters of gas masks. Therefore, referring to the health and safety data, the physico-chemical data as well as the technical feasibility, it was deduced that cyclohexane was taken as the most advantageous candidate and n-heptane as the second among the six candidates.

The second step was the experimental study to prove the applicability of the candidates for replacing $\mathrm{CCl}_{4}$ in the National Approval Test. The requirements are that the breakthrough times of all classes of commercially available and approved respirator cartridges and canisters for cyclohexane vapor should be close to, or kept in a certain ratio with those for $\mathrm{CCl}_{4}$ under various conditions of different concentrations and RH in the test airflow. Because n-heptane has low volatility, the evaporation method was proved to be not applicable to generate the airflow containing 5000 ppm vapor for the examination of FM/BM canisters. So, in 
the present experiment, we examined breakthrough times of all classes of cartridges and canisters which had already been approved to be compliant to the Japanese standards by the National Approval Test for $\mathrm{CCl}_{4}$ and cyclohexane. It was found that the breakthrough times for cyclohexane agreed well with those for $\mathrm{CCl}_{4}$ under various conditions of different vapor concentrations ranging from 120 to $8000 \mathrm{ppm}$ and different $\mathrm{RH}$ conditions ranging from 30 to $80 \%$. The Notification $^{4}$ for standards of gas masks in the National Approval Test stipulates that the breakthrough time of $\mathrm{CCl}_{4}$ be longer than 50 minutes for cartridges when the test airflow of $300 \mathrm{ppm} \mathrm{CCl}_{4}$ passes, longer than $30 \mathrm{~min}$ for chin-style canisters with the test airflow of $3000 \mathrm{ppm} \mathrm{CCl}_{4}$, and longer than $100 \mathrm{~min}$ for FM/BM canisters with the test airflow of $5000 \mathrm{ppm} \mathrm{CCl}_{4}$ at the air flow rate of $30 \mathrm{~L} / \mathrm{min}, 20^{\circ} \mathrm{C}$ and $50 \% \mathrm{RH}$. In the present experiment, breakthrough times of cartridges A and B were $120 \mathrm{~min}$ and $330 \mathrm{~min}$ for $300 \mathrm{ppm}$ cyclohexane, respectively, that of chin-style canister $\mathrm{C}$ was $50 \mathrm{~min}$ for $3000 \mathrm{ppm}$ cyclohexane, and those of FM/BM canisters B and C were $180 \mathrm{~min}$ and $160 \mathrm{~min}$ for $5000 \mathrm{ppm}$ cyclohexane, respectively, which were almost the same as the breakthrough times measured for $\mathrm{CCl}_{4}$ at the same concentrations. The present results mean that the amount of cyclohexane vapor adsorbed on each of the cartridges and canisters up to the breakthrough time was in essential agreement with that of $\mathrm{CCl}_{4}$ vapor adsorbed, and that the affinity of cyclohexane to activated carbon is similar in magnitude to that of $\mathrm{CCl}_{4}$. This speculation can be consistent with the relationship between breakthrough times and adsorptivity of organic vapors by charcoal proposed by Nelson and Harder ${ }^{10)}$.

It is additionally required for the intended change in the testing vapor that the shortening of the breakthrough time for an alternative test vapor in the presence of the increased $\mathrm{RH}$ should be similar to that for $\mathrm{CCl}_{4}$, because it is important to detect the damage of cartridges and canisters due to the moisture accumulation during storage in the national approval test similarly by the examination with the vapor of $\mathrm{CCl}_{4}$. It was found in the present experiment that the breakthrough times of all classes of the commercially available cartridges and canisters observed for cyclohexane were similar to those for $\mathrm{CCl}_{4}$ under all $\mathrm{RH}$ conditions. The present results on $\mathrm{RH}$ effect are consistent with those reported by Moyer and Peterson ${ }^{11}$. It can be interpreted as that cyclohexane and water molecules adsorb competitively on activated carbon in the similar manner as $\mathrm{CCl}_{4}$ and water molecules do. The breakthrough time was defined in this study as the elapsed time from the start of passing the test airflow through a cartridge or canister to the time when the exit vapor concentration reached $10 \mathrm{ppm}$ for both of $\mathrm{CCl}_{4}$ and cyclohexane to compare the results at the same conditions for adsorption.

In conclusion, cyclohexane can be recommended as a $\mathrm{CCl}_{4}$ replacement vapor in the National Approval Test of Gas Mask without changes in the test conditions for generating a test airflow and also without changes in the criteria of gas removing capacities of cartridges and canisters of gas masks.

\section{Acknowledgement}

The authors express their hearty appreciation to Dr. Heihachiro Arito for his encouragement and valuable assistance in discussion and completion of the present study.

\section{References}

1) Singh HB, Salas LJ, Shigeishi H, Scribner E (1979) Atmospheric halocarbons, hydrocarbons, and sulfur hexafluoride: global distribution, sources, and sinks. Science 203, 899-903.

2) Environmental Health Criteria 208 Carbon Tetrachloride p 19-35. IPCS, IOMC, WHO, Geneva 1999.

3) $2000 \mathrm{TLV}$ s and BEIs. Threshold limit values for chemical substances and biological exposure indices. American Conference of Governmental Industrial Hygienists. Cincinnati, U.S.A.

4) The Ministry of Labour Notification No.68 of standards for gas mask. Promulgated on September 26, 1990.

5) The Ministry of Labour Notification No. 1 of standards for gas mask. Promulgated on January 8, 1996.

6) Recommendation of occupational exposure limits (1999-2000). J Occup Health 41, 191-206.

7) ACGIH, Documentation of threshold limit values and biological exposure indices, 1996.

8) Edited by Budavari $\mathrm{S}$ et al, The Merck index, 12th Edition, 1996.

9) Edited by Lide DR et al, CRC Handbook of Chemistry and Physics, 77th Edition, 1996-1997.

10) Nelson GO, Harder CA (1974) Respirator cartridge efficiency studies: V. Effect of solvent vapor. Am Ind Hyg Assoc J 35, 391-410.

11) Moyer ES, Peterson JA (1993) Organic vapor (OV) respirator cartridge and canister testing against methylene chloride. Appl Occup Environ Hyg 8, 55363. 